\title{
Impacts of pore size distribution on gas injection in intraformational water zones in oil sands reservoirs
}

\author{
Jinze $\mathrm{Xu}{ }^{1,2,3}$, Zhangxin $\mathrm{Chen}^{3, *}$, and Ran $\mathrm{Li}^{1,2,3}$ \\ ${ }^{1}$ College of Petroleum Engineering, Xi'an Shiyou University, Xi'an, 710065 Shaanxi, China \\ ${ }^{2}$ Shaanxi Key Laboratory of Advanced Stimulation Technology for Oil \& Gas Reservoirs, Xi'an, 710065 Shaanxi, China \\ ${ }^{3}$ Department of Chemical and Petroleum Engineering, University of Calgary, Calgary, T2N 1N4 Alberta, Canada
}

Received: 31 January 2020 / Accepted: 08 June 2020

\begin{abstract}
Intraformational water zones are widely reported in Canadian oil sands fields. In order to pressurize a thief zone, one of the initiatives is to inject gas. However, the evaluation of gas injectivity based on a pore size distribution is still a big challenge. This study provides a multi-scale approach to study the effect of a pore size distribution on gas injectivity in intraformational water zones. The results indicate the gas effective permeability increases in a less complex and more discrete pore network. The enhancement of gas effective permeability with increased gas saturation weakens with higher complexity and lower discreteness of a pore network. A less complex and more discrete pore network better benefits the gas injectivity index.
\end{abstract}

\section{Introduction}

Over 95\% of oil in Canada is located in oil sands reservoirs. One of the most popular methods to develop the oil sands reservoirs is Steam-Assisted Gravity Drainage (SAGD) (Butler, 1997; Zargar et al., 2020). In this recovery method, two horizontal wells including one injector and one producer are drilled near to the bottom of a reservoir (Butler, 1997). Steam is injected into the upper injector, and the oil is produced from the producer below. A steam chamber grows in this procedure, and the oil flows along the edge of the steam chamber. SAGD has been very successful in Canada, and the oil recovery factor can reach 70\% (Moussa, 2019). However, there are still many challenges during the SAGD production in oil sands reservoirs, and one of them is the gas injectivity evaluation in intraformational water zones.

An intraformational water zone is usually defined as a sandstone zone with its water saturation higher than 0.5 (Xu et al., 2017). Owing to the domination of convective heat flux, steam has its preference to go to water zones instead of oil-rich zones. In this way, an intraformational water zone acts as a thief zone to increase the steam consumption and leads to a high steam-oil ratio and water cut (Fairbridge et al., 2012). In the past, there are many studies to model the mass and heat transport in intraformational water zones. Wang and Leung (2015) applied a random distribution of intraformational water zones to study the effect of different sizes and degrees of continuity. Zhou et al. (2016) derived a model of initial water mobility

\footnotetext{
* Corresponding author: zhachen@ucalgary.ca
}

in intraformational water zones based on a classical capillary model, and their study provided an initial water permeability formula. Ma and Leung (2019) employed a data-driven method to study the effect of intraformational water zones and shale layers, and their study showed the effect of intraformational water zones on production curves. All the previous studies indicate that intraformational water zones are harmful to the SAGD process, and an industrial practice to deal with intraformational water zones is needed. One of the approaches to pressurize the intraformational water zones is gas injection.

Gas injection in oil sands reservoirs has been studied by many scholars in the past decade. Gao et al. (2017) performed a study to select the most appropriate gas to deal with an oil sands reservoir with top water, and they recommended nitrogen for their study area. Yuan et al. (2018) performed experimental and simulation studies to show that a Non-Condensable Gas (NCG) can decrease the consumption of steam and increase an oil rate. Wang et al. (2019) employed an experiment to study the gas injection into an interlayer to improve the SAGD production performance, and their study indicated that a gas addition can help a SAGD steam chamber to break through the interlayer. Austin-Adigio and Gates (2019) performed numerical simulation of NCG co-injection with steam for oil sands recovery, and their study indicated that the oil rate may drop during the NCG injection.

However, the effect of a pore size distribution on gas injectivity in intraformational water zones in oil sands reservoirs is still not explored yet. An understanding of the effect of a pore size distribution will benefit the bridge between 


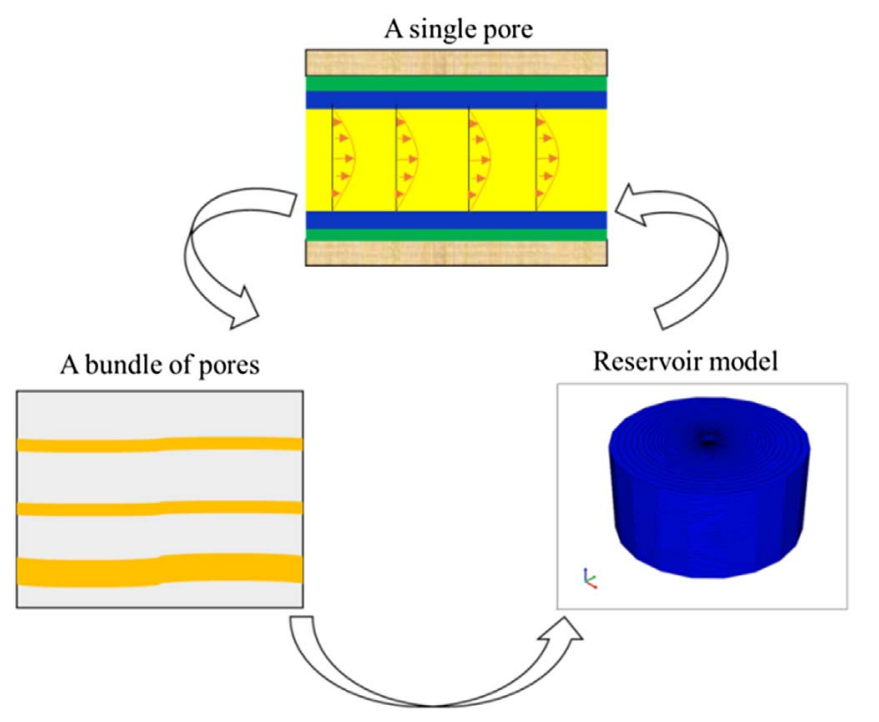

Fig. 1. Workflow of the model establishment in this paper.

geological interpretation and gas injectivity evaluation. This study is focused on a multi-scale approach to evaluate the effect of a pore size distribution on gas injectivity. As shown in Figure 1, an analytical model for gas effective permeability is firstly derived. A gas effective permeability model for a bundle of pores is secondly established. Reservoir simulation is thirdly performed by coupling these models. In this way, the PSD-based gas effective permeability and injectivity index in intraformational water zones in oil sands reservoirs are obtained and analyzed. This study provides a practical workflow to determine the gas injectivity in intraformational water zones in oil sands reservoirs, and provides a strong reference for future oil sands production projects.

\section{Model establishment}

\subsection{Gas-water transport in single pores}

In order to construct an analytical model for gas-water relative permeability curves, we assume that there is no miscibility between oil and water. We thus model the gas-water transport as shown in Figure 2. The gas in this study is methane. Immobile oil sands are attached to the pore wall, and water and gas are in the center. The equations to describe the two-phase transport are shown by equation (1) (Chen et al., 2006):

$$
\left\{\begin{array}{l}
\mu\left[\frac{1}{r} \frac{\partial}{\partial r}\left(r \frac{\partial v}{\partial r}\right)\right]=\nabla P \\
\frac{\partial v_{\mathrm{g}}}{\partial r}=0, \quad r=0 \\
v_{\mathrm{g}}=v_{\mathrm{w}}, \quad r=r_{\mathrm{g}} \\
\mu_{\mathrm{g}} \frac{\partial v_{\mathrm{g}}}{\partial r}=\mu_{\mathrm{w}} \frac{\partial v_{\mathrm{g}}}{\partial r}, \quad r=r_{\mathrm{g}} \\
v_{\mathrm{w}}=0, \quad r=r_{\mathrm{w}}
\end{array}\right.
$$

where $\mu_{\mathrm{w}}$ is the water viscosity, $\mathrm{Pa} \mathrm{s} ; \mu_{\mathrm{g}}$ is the gas viscosity, $\mathrm{Pa} \mathrm{s} ; v_{\mathrm{w}}$ is the water velocity, $\mathrm{m} / \mathrm{s} ; v_{\mathrm{g}}$ is the gas velocity, $\mathrm{m} / \mathrm{s} ; r_{\mathrm{g}}$ is the radius of a gas-flow area, $\mathrm{m} ; r_{\mathrm{w}}$ is the radius of a water-flow area, $\mathrm{m} ; P$ is the pressure, $\mathrm{kPa}$.

By solving equation (1), we can obtain expressions for $v_{\mathrm{g}}$ and $v_{\mathrm{w}}$ as follows:

$$
\left\{\begin{array}{l}
v_{\mathrm{g}}=\left(\frac{r^{2}}{4 \mu_{\mathrm{g}}}+\frac{\mu_{\mathrm{g}} r_{\mathrm{g}}^{2}-\mu_{\mathrm{w}} r_{\mathrm{g}}^{2}-\mu_{\mathrm{g}} r_{\mathrm{w}}^{2}}{4 \mu_{\mathrm{w}} \mu_{\mathrm{g}}}\right) \nabla P \\
v_{\mathrm{w}}=\left(\frac{r^{2}}{4 \mu_{\mathrm{w}}}-\frac{r_{\mathrm{w}}^{2}}{4 \mu_{\mathrm{w}}}\right) \nabla P
\end{array} .\right.
$$

The equations to calculate the flow rates of gas $\left(q_{\mathrm{g}}\right)$ and water $\left(q_{\mathrm{w}}\right)$ in a single pore are as follows:

$$
\left\{\begin{array}{l}
q_{\mathrm{g}}=\int_{0}^{r_{\mathrm{g}}} 2 \pi r v_{\mathrm{g}} \mathrm{d} r \\
q_{\mathrm{w}}=\int_{r_{g}}^{r_{\mathrm{w}}} 2 \pi r v_{\mathrm{w}} \mathrm{d} r
\end{array}\right.
$$

where $q_{\mathrm{g}}$ is the gas flow rate in single pores, $\mathrm{m}^{3} / \mathrm{s} ; q_{\mathrm{w}}$ is the water flow rate in single pores, $\mathrm{m}^{3} / \mathrm{s}$.

By coupling equations (2) and (3), $q_{\mathrm{g}}$ and $q_{\mathrm{w}}$ can be obtained by equation (4):

$$
\left\{\begin{array}{l}
q_{\mathrm{g}}=\frac{2 \pi \mu_{\mathrm{g}} r_{\mathrm{g}}^{4}-\pi \mu_{\mathrm{w}} r_{\mathrm{g}}^{4}-2 \pi \mu_{\mathrm{g}} r_{\mathrm{g}}^{2} r_{\mathrm{w}}^{2}}{8 \mu_{\mathrm{w}} \mu_{\mathrm{g}}} \nabla P \\
q_{\mathrm{w}}=\frac{2 \pi r_{\mathrm{w}}^{2} r_{\mathrm{g}}^{2}-\pi r_{\mathrm{w}}^{4}-\pi r_{\mathrm{g}}^{4}}{8 \mu_{\mathrm{w}}} \nabla P
\end{array} .\right.
$$

The relationship between a flow-area radius and saturation is as follows:

$$
S_{\mathrm{g}}=\frac{\pi r_{\mathrm{g}}^{2}}{\pi r_{p}^{2}}
$$

$$
S_{\mathrm{w}}=\frac{\pi r_{\mathrm{w}}^{2}-\pi r_{\mathrm{g}}^{2}}{\pi r_{p}^{2}}
$$

where $S_{\mathrm{g}}$ is the gas saturation, dimensionless; $S_{\mathrm{w}}$ is the water saturation, dimensionless; $r_{p}$ is the pore radius, $\mathrm{m}$.

By coupling equations (4), (5a), and (5b), the saturationbased flow rate is calculated as follows:

$$
\left\{\begin{array}{l}
q_{\mathrm{g}}=-\frac{\pi \mu_{\mathrm{w}} S_{\mathrm{g}}^{2}+2 \pi \mu_{\mathrm{g}} S_{\mathrm{g}} S_{\mathrm{w}}}{8 \mu_{\mathrm{w}} \mu_{\mathrm{g}}} r_{p}^{4} \nabla P \\
q_{\mathrm{w}}=-\frac{\pi S_{\mathrm{w}}^{2}}{8 \mu_{\mathrm{w}}} r_{p}^{4} \nabla P
\end{array} .\right.
$$

\subsection{Gas-water transport in a bundle of pores}

The fractal theory is applied to describe a pore size distribution and related flow calculations in oil sands reservoirs. Usually, a fractal dimension is from experimental studies such as low nitrogen adsorption experiments. The application of the fractal theory is able to introduce a pore size 

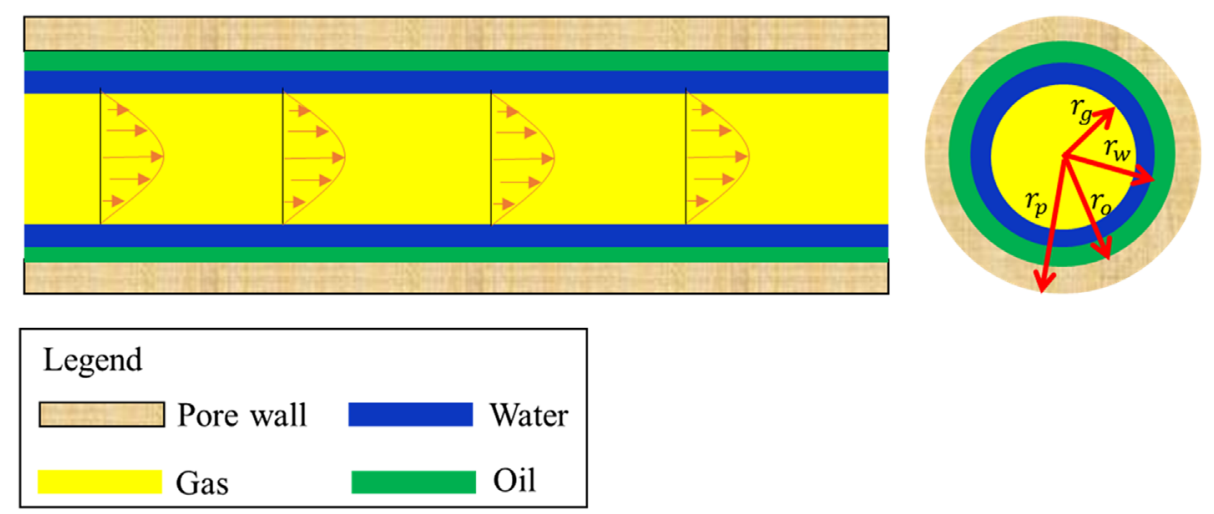

Fig. 2. Scheme of gas-water flow in a single pore.

distribution into a model in single pores. For a bundle of pores with pore radii from $r_{p \min }$ to $r_{p \max }$, the total number of pores based on the fractal theory is as follows: ( $\mathrm{Yu}$ and Li, 2001):

$$
N=\left(\frac{r_{p \max }}{r_{p}}\right)^{D_{p}}
$$

where $N$ is the total number of pores, dimensionless; $r_{p \max }$ is the maximum pore radius, $\mathrm{m} ; D_{p}$ is the fractal dimension, dimensionless.

By integrating the flow rate in single pores based on the fractal theory, we can obtain the flow rate in a bundle of pores as follows (Xu et al., 2018):

$$
\left\{\begin{array}{l}
Q_{\mathrm{g}}=-\frac{\phi}{\tau} \int_{r_{\operatorname{pmin}}}^{r_{\mathrm{pmax}}} q_{\mathrm{g}} \mathrm{d} N \\
Q_{\mathrm{w}}=-\frac{\phi}{\tau} \int_{r_{\mathrm{p} \min }}^{r_{\mathrm{pmax}}} q_{\mathrm{w}} \mathrm{d} N
\end{array},\right.
$$

where $Q_{\mathrm{g}}$ is the gas flow rate in a bundle of pores, $\mathrm{m}^{3} / \mathrm{s}$; $Q_{\mathrm{w}}$ is the water flow rate in a bundle of pores, $\mathrm{m}^{3} / \mathrm{s} ; \phi$ is the porosity, dimensionless; $\tau$ is the tortuosity, dimensionless.

By coupling equations (6)-(8), we can obtain $Q_{\mathrm{g}}$ and $Q_{\mathrm{w}}$ as follows:

$$
\left\{\begin{array}{l}
Q_{\mathrm{g}}=-\frac{\pi \phi D_{p} r_{p \max }^{4}\left(1-\gamma^{4-D_{p}}\right)\left(\mu_{\mathrm{w}} S_{\mathrm{g}}^{2}+2 \mu_{\mathrm{g}} S_{\mathrm{g}} S_{\mathrm{w}}\right)}{8 \tau \mu_{\mathrm{w}} \mu_{\mathrm{g}}\left(4-D_{p}\right)} \nabla P \\
Q_{\mathrm{w}}=-\frac{\pi \phi D_{p} S_{\mathrm{w}}^{2} r_{p \max }^{4}\left(1-\gamma^{4-D_{p}}\right)}{8 \tau \mu_{\mathrm{w}}\left(4-D_{p}\right)} \nabla P
\end{array} .\right.
$$

\subsection{Gas effective permeability for a bundle of pores}

Gas effective permeability is a key parameter to evaluate the gas injectivity, and it can be obtained based on the equivalence between the flow rate in equation (9) and Darcy's law. The flow rate based on Darcy's law can be obtained by equation (10):

$$
\left\{\begin{array}{c}
Q_{\mathrm{gD}}=-\frac{K_{\mathrm{g}} A_{t}}{\mu_{\mathrm{g}}} \nabla P \\
Q_{\mathrm{wD}}=-\frac{K_{\mathrm{w}} A_{t}}{\mu_{\mathrm{w}}} \nabla P
\end{array},\right.
$$

where $A_{t}$ is the total cross-sectional area, $\mathrm{m}^{2}$.

The total cross-sectional area $\left(A_{t}\right)$ is calculated as follows:

$$
A_{t}=-\frac{1}{\phi} \int_{r_{p \min }}^{r_{p \max }} \pi r_{p}^{2} d\left[\left(\frac{r_{p \max }}{r_{p}}\right)^{D_{p}}\right] .
$$

By solving equation (11), $A_{t}$ is obtained as follows:

$$
A_{t}=\frac{\pi D_{p} r_{p \max }^{2}\left(1-\gamma^{2-D_{p}}\right)}{\phi\left(2-D_{p}\right)}
$$

Considering $Q_{\mathrm{gD}}=Q_{\mathrm{g}}$ and $Q_{\mathrm{wD}}=Q_{\mathrm{w}}$, we couple equations (9), (10), and (12), and obtain the gas effective permeability $\left(K_{\mathrm{g}}\right)$ and water effective permeability $\left(K_{\mathrm{w}}\right)$ as follows:

$$
\begin{gathered}
K_{\mathrm{g}}=\frac{\phi^{2} r_{p \max }^{2}\left(2-D_{p}\right)\left(1-\gamma^{4-D_{p}}\right)\left(\mu_{w} S_{\mathrm{g}}^{2}+2 \mu_{\mathrm{g}} S_{\mathrm{g}} S_{\mathrm{w}}\right)}{8 \tau \mu_{\mathrm{w}}\left(4-D_{p}\right)\left(1-\gamma^{2-\mathrm{D}_{p}}\right)} \\
K_{\mathrm{w}}=\frac{\phi^{2} S_{\mathrm{w}}^{2} r_{p \max }^{2}\left(2-D_{p}\right)\left(1-\gamma^{4-D_{p}}\right)}{8 \tau\left(4-D_{p}\right)\left(1-\gamma^{2-D_{p}}\right)}
\end{gathered}
$$

In order to run reservoir simulation, the relative permeability curves need to be provided as follows:

$$
\begin{gathered}
K_{\mathrm{rg}}=\frac{K_{\mathrm{g}}}{K_{a}}, \\
K_{\mathrm{rw}}=\frac{K_{\mathrm{w}}}{K_{a}},
\end{gathered}
$$

where $K_{\mathrm{rg}}$ is the relative permeability of gas, dimensionless; $K_{\mathrm{rw}}$ is the relative permeability of water, dimensionless; $K_{a}$ is the absolute permeability, which equals the 
effective permeability of water at the water saturation of $1, \mathrm{~m}^{2}$.

\subsection{Gas injectivity calculations in reservoir simulation}

An effective permeability-based gas injectivity is a general way to evaluate the capacity of gas injection in oil and gas reservoirs (Hu et al., 2017; Ru et al., 2019; Yu et al., 2019). In this stage, the CMG STARS software is employed to couple the analytical models to evaluate gas injectivity in lean zones. The calculation procedure is as follows:

1. Initialize pressure, temperature and saturation distributions;

2. Determine the pore size distribution parameters $\left(r_{p \max }, \gamma\right.$, and $\left.D_{p}\right)$

3. Initialize the relative permeability based on equations (14a) and (14b);

4. Simulation is performed in STARS, and pressure is updated in each of blocks;

5. Update relative permeability curves and go to next time step until the end-time is reached.

6. Calculate the gas injectivity index $\left(J_{\mathrm{g}}\right)$ as follows:

$$
J_{\mathrm{g}}=\frac{Q_{\mathrm{inj}}}{P_{\mathrm{BH}}-P_{\text {Perf }}},
$$

where $J_{\mathrm{g}}$ is the gas injectivity index, $\mathrm{m}^{3} /(\mathrm{Pa} \mathrm{s}) ; P_{\mathrm{BH}}$ is the well bottom-hole pressure, $\mathrm{Pa} ; P_{\text {Perf }}$ is the pressure at a perforation point, $\mathrm{Pa}$.

In these parameters, the porosity, fractal dimension, minimum pore size and maximum pore size are obtained from experiments while the bottom hole pressure and injection rate are from field tests.

\section{Results and discussion}

In this section, effects of a pore size distribution on gas effective permeability and the injectivity index are studied. Values of parameters in calculations are summarized in Table 1.

In a fractal oil sands rock, a higher fractal dimension represents a more complex pore network. As shown in Figure 3a, with an increase in the fractal dimension, the gas effective permeability is trending down. For instance, under a gas saturation of 0.3 , the gas effective permeabilities are $0.2947 \mathrm{D}, 0.2481 \mathrm{D}$, and $0.2071 \mathrm{D}$ when the fractal dimensions are 2.1, 2.2, and 2.3, respectively. This is because larger pores are more probable to exist with a smaller fractal dimension under the same pore radius as shown in Figure 3c. For instance, the cumulative probabilities of a pore size more than 5 um are $0.0600,0.0574$, and 0.0547 under the fractal dimensions of 2.1, 2.2, and 2.3, respectively. Figure $3 \mathrm{~b}$ shows that the enhancement of gas effective permeability with increased water saturation weakens while the fractal dimension increases. For example, $d\left(K_{\mathrm{g}}\right) / d\left(S_{\mathrm{g}}\right)$ is $1.97 \mathrm{D}, 1.66 \mathrm{D}$, and $1.38 \mathrm{D}$ when the fractal dimensions are 2.1, 2.2, and 2.3, respectively. Overall, the
Table 1. Values of parameters in results and discussion.

\begin{tabular}{lcc}
\hline Parameter & Symbol & Value \\
\hline Porosity & $\phi$ & 0.2 \\
Tortuosity & $\tau$ & 1.5 \\
Maximum pore radius & $r_{p \max }$ & $100 \mathrm{um}$ \\
Average pore radius & $r_{p \text { avg }}$ & $2.5 \mathrm{um}$ \\
Fractal dimension & $D_{p}$ & 2.1 \\
Initial oil saturation & $S_{\mathrm{o}}$ & 0.5 \\
Initial water saturation & $S_{\mathrm{w}}$ & 0.4 \\
Connate water saturation & $S_{\mathrm{wc}}$ & 0.1 \\
Reservoir radius & $r_{R}$ & $500 \mathrm{~m}$ \\
Reservoir thickness & $h$ & $10 \mathrm{~m}$ \\
Reservoir Initial Pressure & $P_{R}$ & $100 \mathrm{MPa}$ \\
Gas injection rate & $Q_{\mathrm{inj}}$ & $50 \mathrm{~m}^{3} /$ day \\
\hline
\end{tabular}

gas effective permeability increases when a pore network is less complex, and the permeability enhancement with increased water saturation weakens in a more complex pore network. In a fractal rock, a higher variance indicates a more discrete pore network. Figure 4a shows that the gas effective permeability increases with an increase in variance. Especially, the gas effective permeability increases from $0.41 \mathrm{D}$ to $0.91 \mathrm{D}$ under a gas saturation of 0.5 when the variance increases from $5 \mathrm{um}^{2}$ to $50 \mathrm{um}^{2}$. The reason behind this can be explained by the pore size distribution in Figure $4 \mathrm{c}$, which indicates that the existence of larger pores is more frequent with a larger variance under the same average pore radius as a larger variance yields a more discrete distribution. The cumulative probabilities of a pore size more than 5 um are $0.0087,0.0114$, and 0.0146 under the variances of $5 \mathrm{um}^{2}, 10 \mathrm{um}^{2}$, and $50 \mathrm{um}^{2}$, respectively. A more frequent occupation of larger pores better benefits the gas flow capacity. Figure 4b indicates that the enhancement of the gas effective permeability is more significant with a bigger variance. Especially, $\mathrm{d}\left(K_{\mathrm{g}}\right) / \mathrm{d}\left(S_{\mathrm{g}}\right)$ decreases from 2.80 to 1.26 when variance increases from 2.1 to 2.3 under a gas saturation of 0.4 . In summary, the gas effective permeability increases in a more discrete pore network, and the enhancement of the gas effective permeability with increased water saturation strengthens in a more discrete pore network.

The gas effective permeability directly determines the gas injectivity in intraformational water zones in oil sands reservoirs. Figure $5 \mathrm{a}$ shows that the gas injectivity index increases with time; this is because the gas saturation gradually increases with time, which leads to higher gas effective permeability. The gas injectivity index increases with a decrease in the fractal dimension. For instance, the gas injectivity index is $628.5 \mathrm{~m}^{3} /\left(\mathrm{Pa}\right.$ day), $529.2 \mathrm{~m}^{3} /(\mathrm{Pa}$ day $)$ and $441.2 \mathrm{~m}^{3} /(\mathrm{Pa}$ day $)$ under the fractal dimensions of 2.1, 2.2 and 2.3, respectively. This relationship is due to an increase in gas effective permeability with a decrease in fractal dimensions as shown in Figure 3a. Figure 5b indicates that a higher variance in a pore size distribution better benefits the gas injectivity. Especially, the gas injectivity index increases from $437.5 \mathrm{~m}^{3} /(\mathrm{Pa}$ day $)$ to 

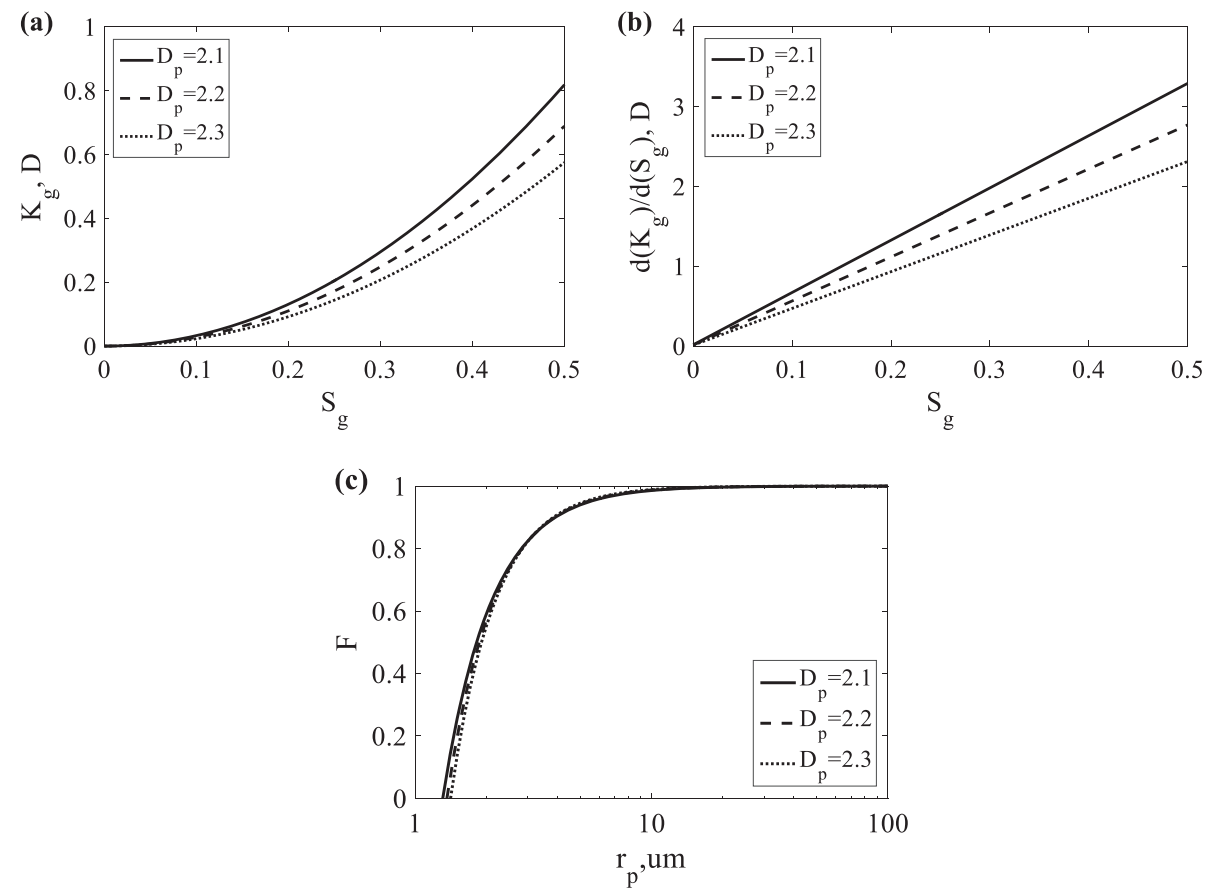

Fig. 3. (a) Relationship between gas effective permeability and gas saturation under different fractal dimensions, (b) relationship between $\mathrm{d}\left(K_{g}\right) / \mathrm{d}\left(S_{g}\right)$ and gas saturation under different fractal dimensions, and (c) relationship between cumulative probability and pore radius under different fractal dimensions.
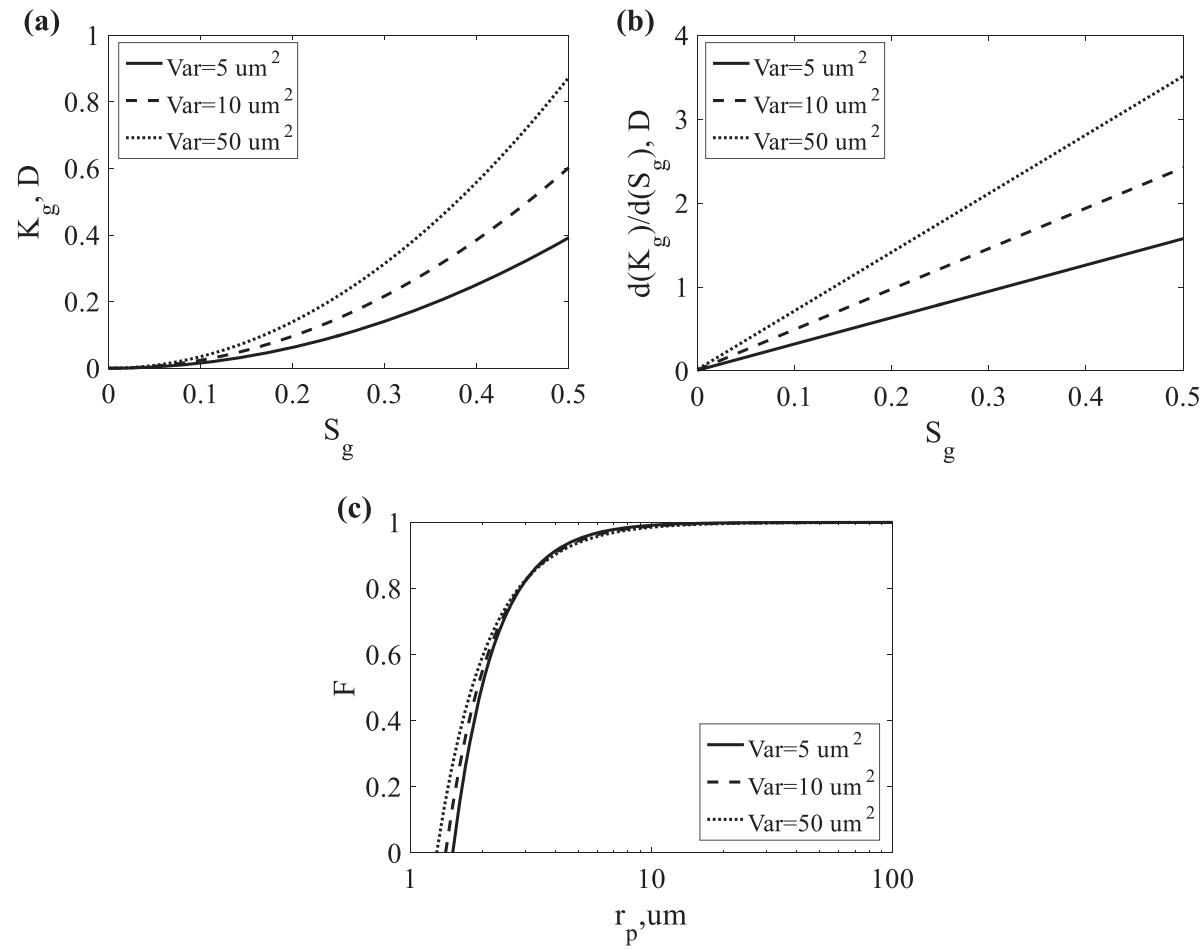

Fig. 4. (a) Relationship between gas effective permeability and gas saturation under difference variances, (b) relationship between $\mathrm{d}\left(K_{g}\right) / \mathrm{d}\left(S_{g}\right)$ and gas saturation under different variances, and (c) relationship between cumulative probability and pore radius under different variances. 

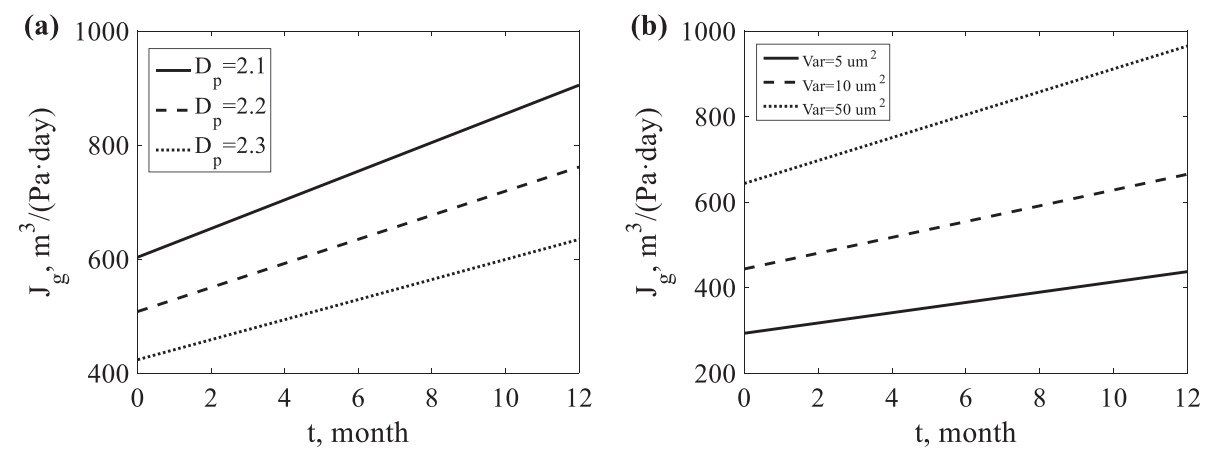

Fig. 5. (a) Relationship between gas injectivity index and time under different fractal dimensions and (b) relationship between gas injectivity index and time under different variances.
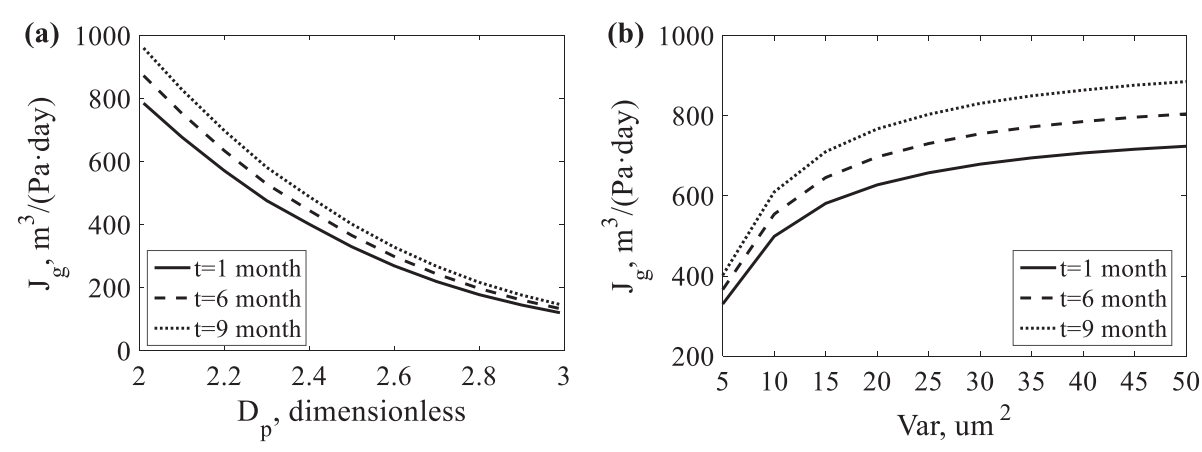

Fig. 6. (a) Relationship between gas injectivity index and fractal dimension at different time and (b) relationship between gas injectivity index and variance at different time.

$965.2 \mathrm{~m}^{3} /(\mathrm{Pa}$ day $)$ when the variance increases from $5 \mathrm{um}^{2}$ to $50 \mathrm{um}^{2}$. This trend is owing to the increased gas effective permeability as shown in Figure 4a. Figure 6a shows a decrease in the gas injectivity index with an increase in the fractal dimension. The impact of the fractal dimension is more significant as time progresses. For instance, the gas injectivity index is $678.1 \mathrm{~m}^{3} /$ (Pa day), $753.7 \mathrm{~m}^{3} /$ (Pa day), and $829.3 \mathrm{~m}^{3} /$ (Pa day) at the time of 1 month, 6 months, and 9 months, respectively, when the fractal dimension equals 2.1. Figure 6a also indicates that when the fractal dimension increases, the sensitivity of gas injectivity to the fractal dimension decreases, which is in agreement with the conclusion from Figure $3 \mathrm{~b}$. Figure $6 \mathrm{~b}$ shows the enhanced gas injectivity index with the increased variance. This is because of the increased gas effective permeability as shown in Figure 4b. Besides, the gas injectivity index is less sensitive to the variance with an increased variance. Thus, the gas injectivity index is greater in a more discrete and less complex pore network. With an increase in complexity and discreteness, the sensitivity of the gas injectivity index to complexity and discreteness of a pore network decreases.

\section{Conclusion}

In this study, an analytical model for gas effective permeability is established for single pores and a bundle of pores, and numerical simulation is further performed to evaluate the gas injectivity index in intraformational water zones in oil sands reservoirs. Our novel methodology is to explore the gas injectivity based on the established analytical model and its application in numerical simulation. The following conclusions are drawn from this study:

1. In a more complex pore network with a higher fractal dimension, the gas effective permeability decreases, and the enhancement of gas effective permeability also weakens.

2. The gas effective permeability increases in a more discrete pore network with a higher variance, and the enhancement of the gas effective permeability with increased water saturation strengthens.

3. A less complex and more discrete pore network better benefits the gas injectivity index. The sensitivity of the gas injectivity index to complexity and discreteness decreases with an increase in the fractal dimension and variance.

Acknowledgments. The research is supported by the National Natural Science Foundation of China (No. 52004220), the NSERC/Energi Simulation and Alberta Innovates Chairs at the University of Calgary.

\section{References}

Austin-Adigio M., Gates I. (2019) Non-condensable gas co-injection with steam for oil sands recovery, Energy 179, $736-746$. 
Butler R. (1997) Thermal recovery of oil and bitumen, GravDrain's Blackbook.

Chen Z., Huan G., Ma Y. (2006) Computational methods for multiphase flows in porous media. Computational science and engineering series, Vol. 2, SIAM, Philadelphia.

Fairbridge J.K., Cey E., Gates I.D. (2012) Impact of intraformational water zones on SAGD performance, J. Pet. Sci. Eng. 82, 187-197.

Gao Y., Guo E., Zhang Y., Shen D., Shi J. (2017) Research on the selection of NCG in improving SAGD recovery for superheavy oil reservoir with top-water, in: SPE Kuwait Oil \& Gas Show and Conference, 15-18 October, Kuwait City, Kuwait, Society of Petroleum Engineers.

Hu J., Zhang C., Rui Z., Yu Y., Chen Z. (2017) Fractured horizontal well productivity prediction in tight oil reservoirs, J. Pet. Sci. Eng. 151, 159-168.

Ma Z., Leung J.Y. (2019) Integration of data-driven modeling techniques for lean zone and shale barrier characterization in SAGD reservoirs, J. Pet. Sci. Eng. 176, 716-734.

Moussa T. (2019) Performance and economic analysis of SAGD and VAPEX recovery processes, Arab. J. Sci. Eng. 44, 6, 6139-6153.

Ru Z., An K., Hu J. (2019) The impact of sulfur precipitation in developing a sour gas reservoir with pressure-sensitive effects, Adv. Geo-Energy Res. 3, 3, 268-276.

Wang C., Leung J. (2015) Characterizing the effects of lean zones and shale distribution in steam-assisted-gravity-drainage recovery performance, SPE Reserv. Evalu. Eng. 18, 3, 329-345.
Wang Z., Li Z., Sarma H.K., Xu Y., Wu P., Yang J., Lu T. (2019) A visualization experimental study on gas penetration through interlayer to improve SAGD performance, J. Pet. Sci. Eng. 177, 959-970.

Xu J., Chen Z., Dong X., Zhou W. (2017) Effects of lean zones on steam-assisted gravity drainage performance, Energies 10, $4,471$.

Xu J., Wu K., Li R., Li Z., Li J., Xu Q., Chen Z. (2018) Real gas transport in shale matrix with fractal structures, Fuel 219, 353-363.

Yu B., Li J. (2001) Some fractal characters of porous media, Fractals 9, 3, 365-372.

Yu Y., Chen Z., Xu J. (2019) A simulation-based method to determine the coefficient of hyperbolic decline curve for tight oil production, Adv. Geo-Energy Res. 3, 4, 375-380.

Yuan Z., Liu P., Zhang S., Li X., Shi L., Jin R. (2018) Experimental study and numerical simulation of nitrogenassisted SAGD in developing heavy oil reservoirs, J. Pet. Sci. Eng. 162, 325-332.

Zargar Z., Razavi S.M., Ali S.F. (2020) Analytical model of steam-assisted gravity drainage (SAGD) process in relation to constant injection rate, Fuel 265, 116772.

Zhou W., Chen S., Dong M. (2016) Novel insights on initial water mobility: Its effects on steam-assisted gravity drainage performance, Fuel 174, 274-286. 